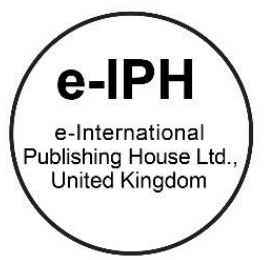

\title{
Enhancing Quality of Life: Restorative Experience in Recreational Forests in Selangor, Malaysia
}

\author{
Norhuzailin Hussain*, Faziawati Abdul Aziz \\ Department of Landscape Architecture, Faculty of Design and Architecture,UPM,43400 Serdang, Selangor, Malaysia
}

\begin{abstract}
Two recreational forests were selected as case studies: The Ampang and Kanching Recreational Forests. The recreational forests are facing pressure by surrounding developments such as highway and housing. Urban development has implications for the benefits offered by recreational forests, endangered biodiversity, water quality and wildlife to result a place that is no longer enjoyable to visit. It is important to conserve the recreational forests that can contribute to the urbanites quality of life. Based on the results from the site observations, self-administered questionnaires and in-depth interviews, this paper describes recreational forest users' experience in the recreational forests and what makes they perceived restored while being in the forest. This study helps the recreational forest management and related organizations in conserving, planning and managing recreational forests in providing a positive experience for users that can enhance Malaysian quality of life.
\end{abstract}

(C) 2016. The Authors. Published for AMER ABRA by e-International Publishing House, Ltd., UK. Peer-review under responsibility of AMER (Association of Malaysian Environment-Behaviour Researchers), ABRA (Association of Behavioural Researchers on Asians) and cE-Bs (Centre for Environment-Behaviour Studies), Faculty of Architecture, Planning \& Surveying, Universiti Teknologi MARA, Malaysia.

Keywords: Health; nature; woman; recreation

\section{Introduction}

This paper discusses the Malaysian restorative experience in recreational forests in Selangor. Forests provide ecosystem services such as cultural services and supporting services (Forestry Commission Wales, 2009). The benefits of forests or natural environments to the health and well-being to urban population have been acknowledged by researchers such as Ulrich (1981), Ulrich et al. (1991) and Scopelliti and Vittoria Giuliani (2004).

In Malaysia, not many study highlighting restorative experience in recreational forests. In brief, recreational forests in Peninsular Malaysia are located in non-urbanised areas or the urban periphery in Permanent Forest Estate, offering basic facilities for communities such as recreation, research, and education. The recreational forests have scenic areas or unique

\footnotetext{
* Corresponding author. Tel.: +603-89464054; fax: +603-89460017/89464080.

E-mail address: zailin@upm.edu.my
}

(c) 2016. The Authors. Published for AMER ABRA by e-International Publishing House, Ltd., UK. Peer-review under responsibility of AMER (Association of Malaysian Environment-Behaviour Researchers), ABRA (Association of Behavioural Researchers on Asians) and cE-Bs (Centre for Environment-Behaviour Studies), Faculty of Architecture, Planning \& Surveying, Universiti Teknologi MARA,Malaysia.

DOI: https.//doi.org/10.21834/e-bpj.v1i2.254 
natural features such as river or waterfall (Manual Perhutanan, 2003). They are managed and developed by the Peninsular Malaysia Forestry Department, State Forest Departments, local authorities or private sectors (Hussain, 2014). However, some of them that are located nearby the urban periphery are being pressured by surroundings development including the two selected recreational forests in this study. Urban development has implications for the benefits offered by recreational forests, threatened biodiversity, water quality and wildlife to result a place that is no longer enjoyable to visit. As a result, there will be underutilization of recreational forests in the future (Hussain, 2014).

\section{Research on Restorative Experience and Human Health}

The researchers' approach used in this study is inspired by the Attention Restoration Theory (Art) introduced by Rachel and Stephen Kaplan (Kaplan, \& Kaplan, 1989); and the biophilia hypothesis was popularized by Wilson (1993). There are four characteristics that form restorative environments: Being away, extent, fascination and compatibility (Kaplan, \& Kaplan, 1989). The Biophilia is defined as "the innately emotional affiliation of human beings to other living organisms" (Wilson, 1993, p.31). Most of the research related to biophilia has focused on the positive affect of associating with plants or physical environments, but the negative affect are seldom considered (Grinde, \& Patil, 2009). However, there is a term 'biophobia' used by Ulrich (1993) to describe strong fears on certain objects (such as animals) and situations that threaten humans in the natural environment. The positive attitudes to nature are also influenced by people's memories of childhood visits (O'Brien, 2006). Cultural factors and individual peculiarities may shape the relationship between humans and plants (Hartig, 1993). A great deal of biophilia-related research has been done regarding the design for healing healthcare environments such as the impact of greenery (therapeutic) on restoration from stress (Ulrich, 1981; Ulrich, 2008). A recent study by Bratman and colleagues (2015) around Stanford, California extend the existing research resulted in affective benefits: decreased anxiety, rumination, and negative affect, and preservation of positive affect; as well as cognitive benefits: increased working memory performance when participants experienced the nature walk compared to urban walk. The research above shows that connect with nature directly or indirectly can give benefits that relate to human health such as restoration. There are not many studies discussing the restorative experience in recreational forests in Malaysia, so the aim of this study is to find out what make a restorative experience for Malaysian recreational forest users.

\section{Methods}

\subsection{Research approach}

Mixed methods (site observations, field survey, and in-depth interviews) used to triangulate the data with literature reviews; to validate and strengthen the data. In this paper, results from the field survey and in-depth interviews will be discussed. The observation results will be supported the interview results where relevant. A self-administered questionnaire with two versions: a version in Malay and a version in the English Language were used. There are 6 sections in the questionnaire: Section 1 (Visits to the recreational forest: 9 items), Section 2 (Attitudes towards physical features of the forest: 17 items), Section 3 (Motivation for forest use: 26 items), Section 4 (Feelings when in the forest: 22 items), Section 5 (Expectations towards recreational forest: 15 items) and Section 6 (Demographic information: 7 items).

\subsection{Study area}

Two recreational forests were selected: The Ampang and Kanching Recreational Forests. Ampang Recreational Forest is situated within a predominantly forested area to the east of Kuala Lumpur. Ampang Recreational Forest is located in Ampang Jaya District while Kanching Recreational Forest is located in Rawang District. The forest is a part of a forest reserve, also functions as the water catchment area for the Klang Gates Dam and surroundings intake (Ling, 2011). Both of them have similarities where they are proximate to urban areas, easy to access by walking and another mode of transportation, have similar basic facilities such as toilet and walkways, similar sizes and have rivers. Both forests have much-undisturbed flora and fauna such as forest plant species, wild insects, birds, and monkeys. The differences are that there are seven levels of waterfalls at Kanching Recreational Forest and areas to explore the forest are larger than Ampang Recreational Forest. It has additional facilities such as changing rooms and a few chalets. 


\subsection{Data collection}

Both the questionnaire survey and the in-depth interviews were conducted in the recreational forests concurrently; where the surveys and interviews were conducted simultaneously. Consent letter was used to get permission from respondents and interviewees before the survey and the interviews been conducted. The questionnaire used a five-point scale (1 to 5$)$ ranging from "strongly disagree" (1) to "strongly agree" (5); the midpoint was represented by "not sure" (3).

The questionnaire surveys and interviews were conducted in April, May and early June 2010 at weekdays and on weekends to three ethnicities: Malays, Chinese and Indians. In the end, a total of 413 questionnaires (208 respondents from the Ampang Forest and 205 from the Kanching Recreational Forest) were used for the analysis. The in-depth interviews were based on the similar questions from the questionnaires' sections, however; any differences encountered or new insights were also explored. Forty forest users were interviewed consisting of twenty-three from the Ampang Recreational Forest and seventeen from the Kanching Recreational Forests.

The observations were carried out in Oktober 2009. The purpose of the observations was to obtain a profile of the recreational forests users and their activities.

\subsection{Demographic and socio-economic characteristics}

In general, the questionnaire survey sample consisted mostly of respondents aged between 19-25 and 36-55 years, with higher numbers of males over females. The majority groups of the respondents are the Malays, married people and the employed. The overall gender distribution is a balance between male and female respondents.

\section{Findings}

\subsection{Quantitative results}

The results and discussion answer the objective of this study: 1) to identify factors that influenced users' perceived restorative experience; 2) to examine users' feeling while in the recreational forests.

The data collected from the questionnaire were analyzed and will be discussed following with the interview and observation results where necessary. Principal Components Analysis (PCA) with varimax rotation was used to analyze the data from Sections 2, 3 and 4. The reliability test was conducted to those items. From the scree plot analysis, there were eight factors extracted. However, seven factors were retained because the last factor (factor eight) tends to be less significant. Thus, the seven factors were: "Forest amenities", "Restorative experience", "Intergenerational values", "Self-actualization", "Incivilities", "Natural threats in the forest" and "Younger activity preference". The seven factors accounted for $46.2 \%$ of the total variance. Table 1 shows factor loading for the items fall in the "Restorative experience" category, accounted $7.1 \%$ of the variance with Cronbach's alpha 0.84. De Vellis (2003) categorized Cronbach's alpha value as follows: below 0.60 (unacceptable to use), between 0.60 and 0.65 (undesirable), between 0.65 and 0.70 (minimum acceptable), between 0.70 and 0.80 (respectable), between 0.80 and 0.90 (very good), 0.90 and 1.0 (reducing the items). Thus, the factor two falls into "very good" value. Other five factors are not going to be discussed where they are not relevant to this topic.

Table 1. Items retained under factor 2 ("Restorative experience"), loadings $\leq 0.30$ not shown

\begin{tabular}{l|l}
\hline $\begin{array}{l}\text { Motives for forest use and experience } \\
\text { I prefer to visit a recreational forest: }\end{array}$ & $\begin{array}{l}\text { Factor loadings } \\
\text { Forest amenities }\end{array}$ \\
\hline Where there are boards telling me about the forest & 0.75 \\
\hline That has basic facilities (e.g: toilet, shelter, prayer room) & 0.74 \\
\hline Where there are signs that lead me through the forest & 0.74 \\
\hline Where there are signs that lead me to the forest & 0.74 \\
\hline That is tidy in appearance & 0.70 \\
\hline That has available parking spaces & 0.67 \\
\hline
\end{tabular}




\begin{tabular}{l|l}
\hline That is free of rubbish & 0.65 \\
\hline That is fenced off and has secured environment & 0.64 \\
\hline That is easy to get into & 0.62 \\
\hline That clearly indicates that visitors are welcome & 0.60 \\
\hline Where there are streams, rivers or waterfall & 0.59 \\
\hline Where the paths are free from obstruction & 0.57 \\
\hline That has areas of open space & 0.54 \\
\hline That I can get to by car, bus or motorcycle & 0.50 \\
\hline Motives for forest use and experience* & Factor loadings \\
My reason for visiting the forest is: & Restorative experience \\
\hline To relax and forget my worries & 0.63 \\
\hline To view the scenery & 0.60 \\
\hline To go walking & 0.60 \\
\hline To experience the calm and comfort of a forest & 0.58 \\
\hline To experience the silence of the forest & 0.53 \\
\hline I feel alive: I can be in contact with the elements of nature & 0.52 \\
\hline To lift my spirits when I am depressed & 0.49 \\
\hline To watch birds and animals & 0.45 \\
\hline To get fresh air & 0.43 \\
\hline To enjoy the sights, smell and sounds of nature (e.g. insects, & 0.39 \\
birds, water ,etc.) & \\
\hline
\end{tabular}

${ }^{* *}$ Originally coded on a 5-point Likert-type scale where: $(1)=$ strongly disagree,

$(2)$ = disagree, $(3)=$ not sure, $(4)=$ agree, $(5)=$ strongly agree .

This factor shows that restorative experience may influence by the forest amenities and the activities they engaged in; also from the physical forest's environment. The respondents preferred to come to the forests that have basic facilities, secured, proper signage to give informations or lead through the forests, tidy appearance and easy to access. The most attractions in both recreational forests are the seven-stage waterfalls in the Kanching Recreational Forest and the stream in the Ampang Recreational Forests.

The physical forest environment gives positive effects to the respondents such as relax, calm, feel alive and enjoy while they were in the forest which they perceived as a restorative experience. Some of the items in this factor are also related to the biophilia hypothesis explained earlier where respondents motivated to come to connect with nature and animals. The activities they engaged in give a restorative experience such as fascination, extent, compatibility and being away as stated in the Restorative Attention Theory earlier. For example, they were fascinated by viewing the scenery such as waterfalls, or watching birds or other animals. Some respondents came to experience the silence of the forest can be a being away where they did not want any disturbance. Some of the respondents felt compatible when they can be in contact with the elements of nature such as to get fresh air.

\subsection{Qualitative results}

This section shows the results from the interviews supported by observations results where relevant. Similar with the quantitative results, the interview and observation results also showed that physical characteristics of the recreational forest played an important role that attracted people to visit. For example, in the Kanching Recreational Forest the main attractions were the waterfalls. In addition, a man felt extended when he looked at the great scale of the trees in the forests make him thinking beyond his thought. The key words that repeatedly mentioned about the users' experienced in both recreational forests were "refreshed", "peaceful", "enjoyable", "relaxing", "calm", "recharged", "happy", "fun" and "absence of worry. However, some of the interviewees had negative feelings towards the physical environments, physical character of the elements within the 
recreational forest such as slippery pathway; wild animals such as wild monkeys; and also fears of crime and incivilities such as thick bushes. Only women felt fear towards the wild monkey; a few of men feel excited and fascinated when watching animals in the recreational forests. A few interviewees at Kanching Recreational Forest mentioned about their mixed feelings. For example, they felt enjoyed, but at the same time worried about accidents because of the fear slippery walkway:

"Enjoyable! But when I wanted to go to the waterfall areas, I feel the fear of danger; probably I can fall because the pathway is quite slippery because we need to go up towards the waterfall areas (Malay, 19 years, Kanching Forest).

The interviewees in Ampang Recreational Forest described the restorative experience as feeling calm, being away from mundane chores, recharging the batteries, meditation, and relaxation, and releasing stress compare to Kanching Recreational Forest interviewees. The tranquil ambiance at the Ampang Recreational Forest invited more visiting from those who wants to meditate or take a photo of birds. A few of men came to the forest to have bird watching as a hobby. In contrast, some of the interviewees in the Kanching Recreational Forest more suitable for forest exploration such as climbing hills. Some interviewees there believed that the forest's ambiance could reduce their stress where they felt recharged either from work, studies or household chores, with the result that they felt peaceful and relaxed. They also connected their sense of relaxation with aspects of the forest ambiance such as fresh air or being away. Four interviewees said:

"Can breathe fresh air, more relax" (Chinese, 48 years, Kanching Forest).

"... when we breathe in fresh air, feeling enjoy in the morning. If I am at home, I don't feel [the] enjoyment" (Malay, 29 years, Ampang Forest).

"I think at the same time able to help all of us to recharge from our stress either from works or studies, so gain peace for all of us" (Malay, 40s, Kanching Forest).

"... to get away from the city lifestyle. Because we worked in KL [Kuala Lumpur], very hectic .... So forest is just you ... can get away from those things" (Chinese, 33 years, Kanching Forest).

A few of the interviewees said that when they visited the recreational forests they felt like they were visiting their childhoods place:

"I came here since I think at age 13 at that time. At that time, the areas were not like today. It was seemed a [thick] forest and the road were dirt. I felt the fear of the leeches, so that's why I did not come for a long time. It was muddy, many leeches, no parking, when I came back here, they already tarmac the road" (Chinese, 41 years, Ampang Forest).

"I feel enjoyable because we already had experience when we were small, right." 'We left the experience a long time ago, when [being] here we feel the experience and recall the memory" (Malay, 30s, Kanching Forest).

Restorative experience also experienced through direct interactions by engaging in activities, such as taking photographs, viewing natural scenery/wild animals, swimming, going fishing and viewing people and surroundings. Through those activities, the interviewees could use all of their five senses that could give enjoyable benefits and immerse themselves in those activities. For example, swimming could give some interviewees to interact with the physical character of the cool and clean water, and their children could have an opportunity to swim and play in the water:

"My family and I swim here. The water feels cool" (Indian, 34 years, Kanching Forest).

In Ampang Recreational Forest, many interviewees motivated to come for fitness and health gained from activities such as brisk walking, meditation, cycling, and tai-chi. Usually the Chinese users and elderly people preferred to engage in such activities. On the other hand, some interviewees liked to climb hills and jungle trekking to improve their health:

"Today I come to strengthen my leg by climbing the hill. It is more to build up the stamina, for health and to balance back my weight (to get back his ideal weight)" (Malay, 30s, Kanching Forest).

Observations revealed that exercise related activities such as jogging was more popular at Ampang Recreational Forest, while picnicking/barbeque (BBQ) was more popular in Kanching Recreational Forest. Some of the users in Ampang Recreational Forests were also did meditation activities. Cycling was observed in Ampang Recreational Forest because boys and occasionally male adults, from residential areas nearby regularly cycled there. On the other hand, most of the adult women except female teenagers appeared to be busy serving food or attending to their family's needs.

Companions while doing the activities is also influence the interviewees' feelings when they were in the forests. Both interview and observation results revealed that most of the users visited the forests with family members or friends to enjoy the activities and to bond with others. For example, two interviewees said:

"The purpose we come here is to enjoy the activities together. If I go [come] alone, no point! We are sharing" (Chinese, 29 years, Ampang Forest). 
"Uncomfortable! ... because if I am alone, there is no companion, we need many companions, so be together with friends, enjoy the nature with friends" (Malay, 43 years, Ampang Forest).

\section{Discussion}

Both the quantitative and qualitative results show that there are a few similarities regarding the restorative experience in Malaysia with the Western countries that will be explained later. However, there is a significant difference with the physical forest's environments and climate that made the activities forest users engaged in are the difference.

Malaysian visited the recreational forests to fulfill their innate need to contact natural elements such as water and plants as stated in the biophilia hypothesis. Forest amenities are very important to motivate people to use the recreational forests, and provide opportunities for engaging certain activities such as swimming or doing exercise such as jogging. Both recreational forests are unique in their characteristics that attract people to come such as waterfalls in Kanching Recreational Forest and a stream in Ampang Recreational Forest. Ward Thompson et al.'s (2014) study in Glasgow indicated that human's health and wellbeing benefits may derive from the opportunity that green space affords for physical activity. To attract people frequently come, the forest management should maintain the facilities provided such as toilets and amenities are in good condition and safe to use.

The physical aspect of a recreational forest is very important in creating an ambiance that gives restoration affects. The cool and refreshing air gives comfort to users. Recent evident from Bratman et al.'s (2015) study show that the respondents who involved with nature walk received more affective and cognitive benefits than those who engaged in an urban walk. A sense of attachments towards the physical aspect from childhood experience may also contribute to the experience.

Results also show the forest users perceived restorative through direct or indirect contact with nature. For example, direct engagement involves the physical activities such as jungle trekking or swimming in the cool water that could give satisfaction regarding users' wellbeing. While, indirect contact is by observing people and surrounding forest, hearing the sound of nature such as waterfalls or insects, the smell of forests also may contribute to the restorative experience. By engaging in the recreational activities, users felt positive affect such as restored and positive feelings such as enjoyable and calmness. Some users such as women had either negative or mixed feelings towards the situations and certain objects such as wild monkey that may relate to 'biophobia' as mentioned by Ulrich (1993). Those feelings may deter women users to have much experience and did not make full use of the recreational forests.

Social factors such as interactions with family members while doing recreational or leisure activities may also contribute to the restorative experience. Through such activities, the users can have bonding between their family members or friends. Perhaps there are social integrations among users with different ethnicities background. The question is how to sustain those restorative experiences so that the future generations could have the similar experience? It is important that current and future society can experience the restoration effects while visiting recreational forest so that Malaysian government will spend less on medication and hospitalization; resulting future generation that are healthy physically and mentally. Therefore, the conservation and preservation of recreational forests are very crucial. This study may give some implications on sustainable use of recreational forests in Malaysia and the Malaysian's wellbeing. Furthermore, recreational forests are also potential space for social cohesion amongst users.

\section{Conclusion and Recommendation}

This study supports previous research where nature environments such as the recreational forests can give restorative experiences to the users. Although the restorative experience common to many cultures, it is very context specific because results presented earlier have shown that in Malaysia it has distinctive local characteristics. Thus, there is much more to find out about the unique characteristics of the restorative experience in different localities. Therefore, it is important to conserve and preserve the existing physical characteristics of the recreational forests so that they can offer benefits such as being away, extent and contemplate to those who need that and also future generation. It is also important to have recreational forests that are proximate to surrounding communities where they can give an opportunity for people to engage with physical activities and experience the forest. This can enhance their quality of life and wellbeing. It is suggested the Peninsular Malaysia Forest Department can create more recreational forest nearby a residential area in an urban setting that can provide physical activity to the urban populations. Forest managers need to manage, plan and conserve the recreational forests in Peninsular Malaysia in 
providing a positive experience such as restorative for users that can enhance Malaysian quality of life. This study is limited to the users' restorative experiences and feelings while they were in the recreational forests, thus, it is suggested to focus in detail about the gender effects and restorative experience in other natural environments such as wetlands using qualitative approach.

\section{Acknowledgements}

The authors thank the Ministry of Higher Education (MOHE), Malaysia and Universiti Putra Malaysia for funded this study.

\section{References}

Bratman, G.N., Daily, G.C., Levy, B.J., \& Gross, J.J. (2015). The benefits of nature experience: Improved affect and cognition. Landscape and Urban Planning, $138,41-50$.

De Vellis, R.F. (2003). Scale Development: Theory and Applications (2nd ed.). London, Sage Publications Inc.

Forestry Commision Wales. (2009). Woodlands for Wales. Welsh Assembly Government, United Kingdom. ISBN 978-0-7504-5034-8.

Grinde, B., \& Patil, G.G. (2009). Biophilia: Does visual contact with nature impact on health and well-being?. International Journal of Environmental Research and Public Health, 6, 2332-2342.

Hartig, T. (1993). Nature experience in a transactional perspective. Landscape and Urban Planning, 25, 17-36.

Hussain, N. (2014). Use and experience in two recreational forests in Selangor state, Malaysia: The impact of age, gender and ethnicity. Unpublished PhD Thesis. The University of Sheffield.

Kaplan, R., \& Kaplan, S. (1989). The experience of nature: A psychological perspective. New York, Cambridge University Press.

Ling, G. P. 2011. NGOs: No to KLORR, protect Selangor State Park. Selangor Times, Dec 31, 2010-Jan 2, 2011.

Manual Perhutanan. (2003). Jilid i 2005. Jabatan Perhutanan Semenanjung Malaysia. Ampang Press Sdn. Bhd.

O’Brien, E. (2006). Social housing and green space: A case study in Inner London. Forestry, 79, 535-551.

Scopelliti, M. \& Vittoria Giuliani, M. (2004). Choosing restorative environments across the lifespan: A matter of place experience. Journal of Environmental Psychology, 24, 693-712.

Ulrich, R.S. (1981). Natural versus urban scemnes: Some psychopsiological effects. Environment and Behavior, 13, 523-556.

Ulrich, R.S. (1993). Biophilia, biophobia, and natural landscapes. In S.R. Kellert \& E.O. Wilson (Eds.), The biophilia hypothesis (73-137). USA: Island Press.

Ulrich, R.S. (2008). Biophilic theory and research for healthcare design. In S.R. Kellert, J.H. Heerwagen \& M.L. Mador (Eds.), Biophilic design: The theory, science, and practice of bringing buildings to life (pp. 87-106). New Jersey: John Wiley.

Ward Thompson, C., Aspinall, P. \& Roe, J. (2014). Acces to green space in disadvanteged urban communities: Evidence of salutogenic effects based on biomarker and self-report measures of wellbeing. Procedia-Social and Behavioral Sciences, 153, 10-22.

Wilson, E.O. (1993). The Biophilia Hypothesis. In S. R. Kellert \& E. O. Wilson (Eds.), Biophilic and the conservation ethic (pp. 31-69). Washington: Island Press. 